\title{
Integração entre os cursos de medicina e de enfermagem nas escolas de saúde no estado do Paraná
}

\author{
Integration between medicine and nursing schools in the state of Paraná \\ Integración entre los cursos de medicina y de enfermería en las escuelas de \\ salud en el estado del Paraná
}

Vilma Mittman Leão ${ }^{1}$, Leide da Conceição Sanches ${ }^{2}$, Viviane Maria Penteado Garbelini ${ }^{3}$, Elaine Rossi Ribeiro", Maria Cecilia Da Lozzo Garbelinis"(")

${ }^{1}$ Enfermeira da Prefeitura Municipal de Corbélia - PR

${ }^{2}$ Doutora em Sociologia pela Universidade Federal do Paraná. Docente do Programa de Mestrado em Ensino nas Ciências da Saúde da Faculdades Pequeno Príncipe Curitiba-PR

${ }^{3}$ Doutora em Engenharia de Produção. Mestre em Educação. Coordenadora Operacional de Educação a Distância na Pontifícia Universidade Católica do PR

${ }^{4}$ Doutora em Medicina pela Universidade Federal do Paraná. Docente do Programa de Mestrado em Ensino nas Ciências da Saúde da Faculdades Pequeno Príncipe Curitiba-PR

${ }^{5}$ Doutora em Ciências pela Universidade Federal do Paraná. Docente do Programa de Mestrado em Ensino nas Ciências da Saúde Faculdades Pequeno Príncipe Curitiba-PR

\section{RESUMO}

A integração entre os cursos da área da saúde possibilita um aprendizado conjunto das temáticas em comum e das que podem se complementar permitindo o trabalho em equipe. Objetivou-se identificar as diversas formas de integração aplicadas pelos docentes dos cursos de enfermagem e medicina, comparando as estratégias de integração utilizadas com a literatura publicada na área. A pesquisa foi transversal, descritiva e exploratória, com abordagem quantitativa. Os participantes foram os coordenadores dos cursos de medicina e enfermagem, atuantes em IES localizadas no Estado do Paraná. Os dados coletados revelaram que há iniciativas isoladas e extracurriculares nas IES, quanto à promoção de temáticas comuns entre os cursos. Considera-se pelos resultados obtidos que a integração entre os cursos pesquisados continua sendo desafiadora e necessária, pois é desta forma que se torna possível 
uma real e efetiva educação interprofissional para reforçar as atitudes para o trabalho em equipe, sobretudo entre enfermeiros e médicos.

Palavras-chave: Ensino. Faculdades de Medicina. Escolas de Enfermagem. Capacitação Profissional.

\begin{abstract}
The integration among undergraduate health sciences courses allows a joint learning of the themes in common and ofthose that can complement each other, enhancing team work. This study aimed to identify different forms of integration applied by nursing and medicine undergraduate courses professors, comparing the integration strategies used with the literature published in the area. The research was cross-sectional, descriptive and exploratory, with a quantitative approach. The participants were medicine and nursing undergraduate courses coordinators, acting in higher education institutions (HEI) in the State of Paraná. The data obtained revealed that there are isolated and extracurricular initiatives in the HEI, regarding the promotion of common topics between the courses. The results obtained showed that the integration between the studied courses continues to be challenging and necessary, since it is this way that a real and effective interprofessional education becomes possible to reinforce attitudes towards teamwork, especially between nurses and physicians.
\end{abstract}

Keywords: Teaching. Schools, Medical. Schools, Nursing. Professional Training.

\title{
RESUMEN
}

La integración entre los cursos del área de la salud posibilita un aprendizaje conjunto de las temáticas en común y de las que pueden complementarse permitiendo el trabajo en equipo. Se objetivó identificar las diversas formas de integración aplicadas por los docentes de los cursos de enfermería y medicina, comparando las estrategias de integración utilizadas con la literatura publicada en el área. La investigación fue transversal, descriptiva y exploratoria, con abordaje cuantitativo. Los participantes fueron los coordinadores de los cursos, actuantes en IES ubicadas en el Estado de Paraná. Los datos revelaron que hay iniciativas aisladas en las IES, en relación a la promoción de temáticas comunes entre los cursos. Se considera por los resultados obtenidos que la integración entre los cursos sigue siendo desafiadora y necesaria, pues de esta forma se hace posible una real y efectiva educación interprofesional para reforzar las actitudes para el trabajo en equipo.

Palabras clave: Enseñanza. Facultades de Medicina. Escuelas de Enfermería. Capacitación profesional.

\section{INTRODUÇÃo}

A integração dos cursos de Medicina e Enfermagem possibilita a interação entre os futuros profissionais de saúde, na condução de suas ações cotidianas. Para tanto, é necessário o contato com a realidade social e com os problemas reais que os estudantes das áreas de saúde enfrentarão na sua rotina, após o término do curso. Na integração, estudantes dos cursos de Medicina e Enfermagem aprendem as temáticas comuns entre as duas profissões, as quais subsidiam os profissionais a continuarem o trabalho em equipe após a formação 1 .

A literatura aponta que as dificuldades no trabalho 
interprofissional podem ocorrer com a atuação de uma determinada profissão como detentora do conhecimento e responsável pela decisão de ações em saúde, seguindo uma sistemática de hierarquia entre profissões. Embora não seja intencional por parte dos profissionais de saúde, a falta de integração entre as equipes resulta na condição de fragmentação de saberes. Desse modo, se sobressai o modelo assistencial focado na doença e no trabalho biomédico, o que possibilita o predomínio de uma ou mais áreas da saúde sobre as demais, deixando de considerar o indivíduo na sua integralidade.

$\mathrm{Na}$ formação de profissionais de saúde, com ênfase na prática interprofissional, torna-se necessário instrumentalizá-los com recursos, conhecimentos e, ainda, com o respeito ao grau de autonomia e domínio de cada profissão ${ }^{2}$. A integração está relacionada com a fundamentação teórica e a prática, com as metodologias de ensino voltadas para a capacitação de resolução de problemas, que necessitam da atuação em conjunto com diversas áreas de conhecimento ${ }^{3}$.

A formação do profissional da saúde que visa a integração interprofissional com impacto na comunidade, coloca o aluno em contato com a teoria aliada à prática, oportunizando momentos reflexivos nos diferentes períodos de formação. A integração entre as diferentes profissões da área da Saúde tornase necessária diante do fato de que, após a formação, o aluno irá encontrar um ambiente de trabalho com ações que pressupõem uma prática de trabalho em equipe. A delimitação de papéis e a atividade colaborativa entre as profissões se fazem necessárias frente às demandas constantes na área da saúde. No entanto, não se observa um consenso na literatura, assim como as pesquisas são insuficientes para definir o período ideal para que essa integração ocorra. Neste sentido o presente estudo teve como objetivo: identificar como ocorre a integração entre os cursos de enfermagem e medicina e em quais períodos esta integração acontece. Considerando a relevância do tema sobre integração entre as profissões na área da saúde, especificamente nos cursos citados, este estudo procurou responder a seguinte indagação: Ao longo da graduação como ocorre a integração entre os cursos de enfermagem e medicina?

\section{MÉTODO}

Trata-se de uma pesquisa do tipo transversal, descritiva e de caráter exploratório com abordagem quantitativa. O contato com a direção das IES para solicitar a permissão da pesquisa e a posterior aplicação dos questionários aos coordenadores aconteceu entre os meses de agosto e dezembro de 2016. Foi realizado um convite formal aos 22 coordenadores dos cursos de enfermagem e de medicina das 11 escolas de Saúde do Paraná que ofertavam os dois cursos. O procedimento constou do envio por e-mail de uma carta convite juntamente com o link de acesso para o TCLE e para o questionário. Foi necessário aceitar primeiramente participar da pesquisa clicando no aceite do TCLE para, em seguida, ter acesso ao questionário a ser respondido. As IES convidadas pertencem a todas as categorias administrativas: particulares, estaduais, bem como a federal.

O Instrumento de coleta de dados composto de 10 perguntas fechadas, elaborado pelas pesquisadoras e hospedado no google docs, buscou identificar como acontece a integração entre os cursos de enfermagem e medicina, de forma a contribuir para a formação de futuros profissionais, com competência para o trabalho interprofissional. Sabe-se que muitas IES formam separadamente os profissionais que necessitarão trabalhar juntos. Assim, há necessidade de se redirecionar o trabalho em equipe, a integração e valores para o ensino interprofissional, onde duas, ou mais profissões aprendem juntas sobre o trabalho conjunto com um amplo reconhecimento e respeito às especificidades de cada profissão.

As respostas obtidas receberam tratamento estatístico descritivo, a fim de identificar como e em que período dos cursos de enfermagem e medicina ocorre a integração curricular, nas IES que sinalizaram haver 
essa integração. Foi realizada estatística simples, com cálculo de proporções em porcentagem, apresentadas em gráficos e tabelas, elaboradas no programa EXCEL, do Microsoft Office 2007.

A pesquisa seguiu os preceitos éticos da Resolução n 466 de 2012 do Conselho Nacional de Saúde, com aprovação, sob o parecer consubstanciado $\mathrm{n}^{\circ}$ 1.584.164. Os participantes foram informados sobre o caráter voluntário da sua participação na pesquisa, sobre o anonimato, sigilo das informações e da sua autonomia para desistir da pesquisa em qualquer momento que desejassem, sem sofrer prejuízo das suas atividades profissionais.

\section{RESULTADOS}

Considerando que por ocasião da pesquisa havia 11 IES no estado do Paraná que ofereciam os cursos de enfermagem e medicina, esperava-se a participação

Figura 1 - Coordenadores participantes da pesquisa

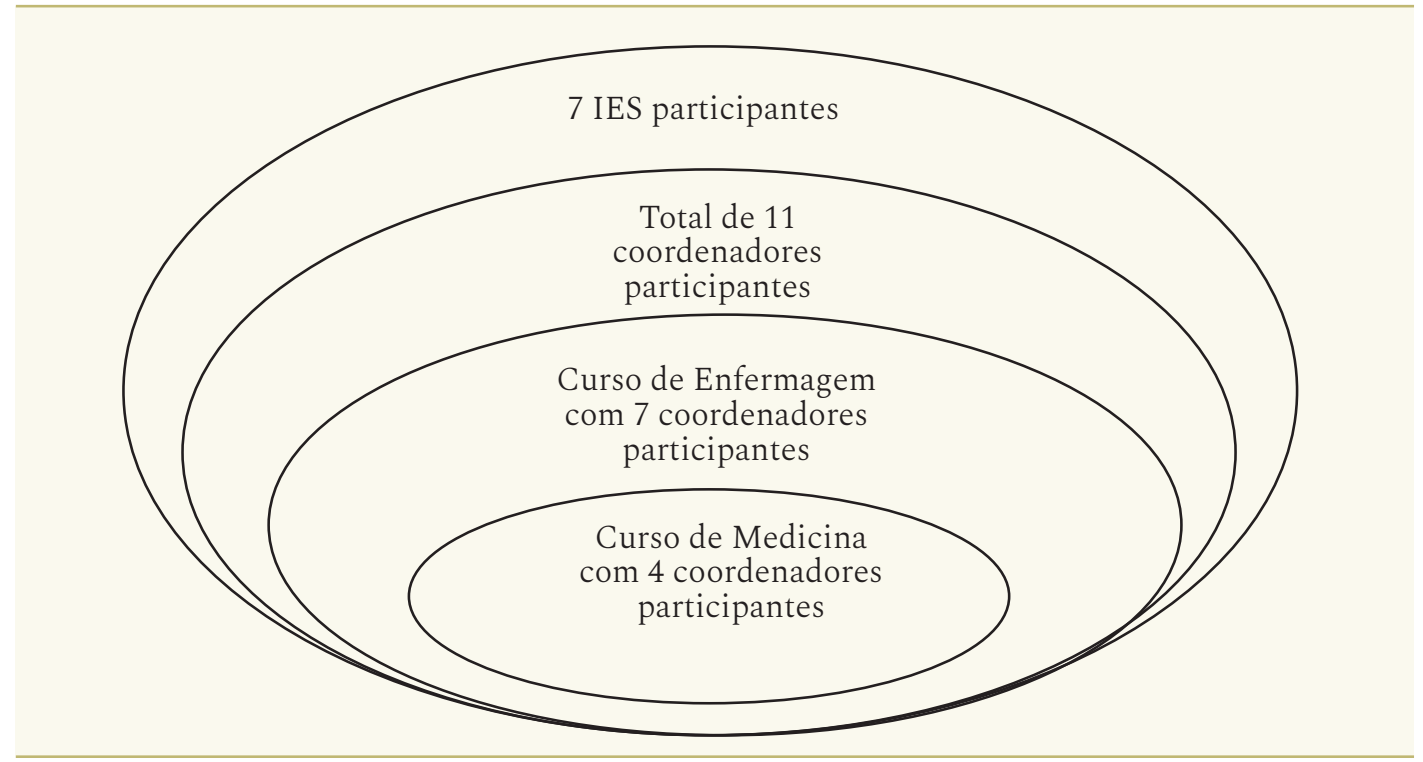

Fonte: As autoras (2017).

Figura 2 - Categoria administrativa das IES

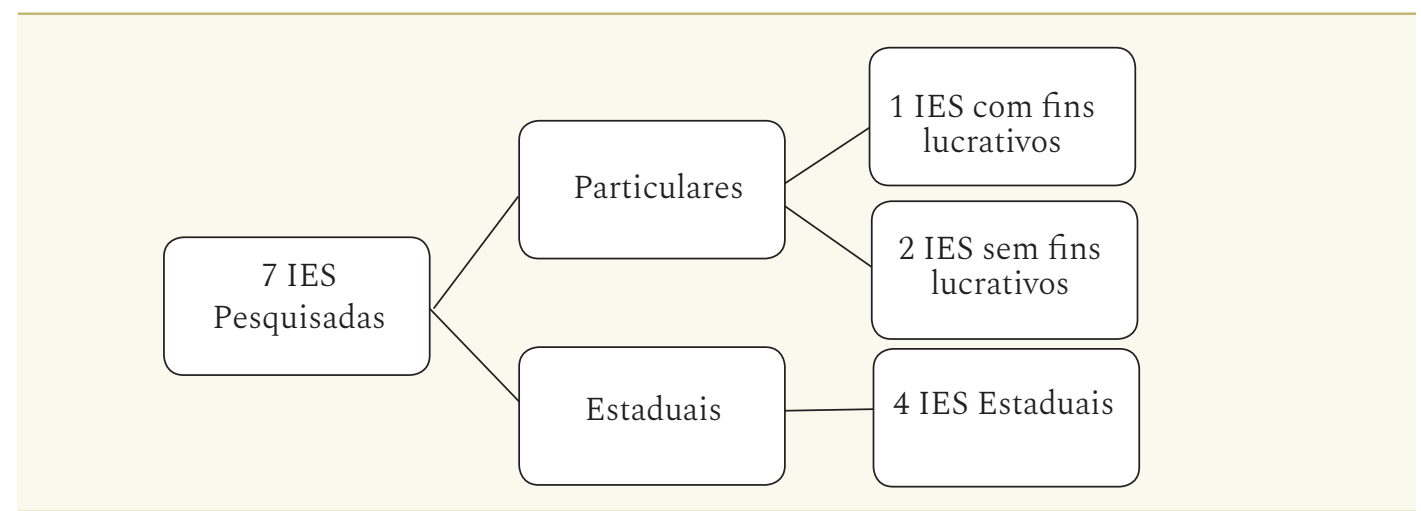

Fonte: As autoras (2017). 
dos 22 coordenadores, contemplando 100\% das IES. Contudo, responderam ao instrumento de coleta de dados 11 coordenadores (07 de enfermagem e 4 de medicina) pertencentes à 07 IES, resultando em um percentual de $64 \%$ de instituições participantes (Figura 1).

Todas as instituições participantes ofereciam os cursos de enfermagem e de medicina há mais de 10 anos. Na figura 2 pode ser observada a categoria administrativa das IES contempladas no estudo.
As respostas afirmativas das 08 perguntas iniciais com percentual acima de $82 \%$, com exceção da pergunta sobre a oferta de disciplinas optativas, identificam que existe alguma forma de integração entre os cursos pesquisados, mostrando uma tendência à utilização de metodologias ativas, embora não apareça na pergunta a palavra integração (Tabela 1). O contexto direciona a uma possibilidade de integração entre os cursos que confirmaram exercer tais atividades, mesmo que isoladamente.

Tabela 1 - Integração entre os cursos de medicina e enfermagem

\begin{tabular}{|c|c|c|c|}
\hline Perguntas & SIM & NÃo & $\begin{array}{c}\text { Não } \\
\text { respondeu }\end{array}$ \\
\hline $\begin{array}{l}\text { 1- Sugestão de Metodologias ativas no } \\
\text { Projeto Pedagógico }\end{array}$ & $82 \%$ & $18 \%$ & $0 \%$ \\
\hline $\begin{array}{l}\text { 2- Projeto Pedagógico direcionado para as } \\
\text { competências colaborativas }\end{array}$ & $100 \%$ & $0,0 \%$ & $0 \%$ \\
\hline $\begin{array}{l}\text { 3- Capacitação de docentes para Integração } \\
\text { Interdisciplinar }\end{array}$ & $82 \%$ & $18 \%$ & $0 \%$ \\
\hline 4- Disciplinas optativas integradas & $64 \%$ & $36 \%$ & $0 \%$ \\
\hline $\begin{array}{l}\text { 5- Currículo permite formação para o } \\
\text { trabalho em equipe }\end{array}$ & $91 \%$ & $9 \%$ & $0 \%$ \\
\hline $\begin{array}{l}\text { 6- Participação das IES no programa PET- } \\
\text { Saúde }\end{array}$ & $91 \%$ & $9 \%$ & $0 \%$ \\
\hline $\begin{array}{l}\text { 7- Atividade de extensão que proporciona o } \\
\text { trabalho em equipe }\end{array}$ & $91 \%$ & $9 \%$ & $0 \%$ \\
\hline $\begin{array}{l}\text { 8- Atividade de pesquisa que proporciona o } \\
\text { trabalho em equipe }\end{array}$ & $82 \%$ & $9 \%$ & $9 \%$ \\
\hline
\end{tabular}

Fonte: As autoras (2017).

\section{DISCUSSÃo}

Inicialmente os coordenadores responderam a seguinte pergunta: O Projeto Pedagógico (PP), do curso que você coordena, sugere a utilização de metodologias ativas com ênfase na aprendizagem significativa como estratégia educativa para o desenvolvimento de conhecimentos, habilidades e atitudes em diferentes cenários de prática interprofissional? Nas respostas foi constatado que nove coordenadores, dentre os quais sete de enfermagem e dois de medicina, sinalizaram afirmativamente, enquanto que dois coordenadores de medicina responderam que o PP não contempla as metodologias ativas. As respostas afirmativas dos pesquisados sinalizam que existe alguma forma de 
integração, mostrando uma tendência à utilização de metodologias ativas, embora não apareça na pergunta a palavra integração. $\mathrm{O}$ contexto direciona a uma ampla possibilidade de sistematizar atividades de integração em instituições que confirmam ter atividades integrativas, mesmo que isoladamente, sem seguir um currículo específico.

Em relação às metodologias ativas, a problematização é utilizada como estratégia de ensino-aprendizagem, com o objetivo de alcançar e motivar o discente. Diante do problema, o aluno se detém, examina, reflete, relaciona a sua história e passa a ressignificar suas descobertas. Neste sentido, o discente é inserido em metodologias onde há exigência da capacidade de tomar decisões e resolver situações, utilizando a problematização. Portanto, trata-se de um novo modelo de ensino com finalidade de adequar o sistema e dar respostas às demandas sociais ${ }^{4}$.

O processo de mudança traz desafios quanto ao fortalecimento ou mesmo fragilidades do ensino que precisam ser trabalhadas para aprimorar o novo modelo. Os estudos relativos apontam que os estudantes de enfermagem e medicina utilizam metodologias ativas para estimular a aprendizagem. No entanto, alguns alunos não estão preparados e se sentem perdidos na busca do conhecimento, principalmente nas disciplinas básicas. ${ }^{5}$ A transformação é necessária e deve ser constante, pois novos modelos requerem empenho não só dos estudantes, mas também dos docentes. Nesse sentido, as metodologias ativas no processo de ensinoaprendizagem utilizadas para a integração entre os cursos de Enfermagem e Medicina estimulam o estudante a organizar sua vida acadêmica, incentivam a pesquisa e a busca pela construção do conhecimento, com direcionamento para a prática do trabalho em equipe, como resultado da integração curricular.

A seguir foi questionado: O Projeto Pedagógico do curso que você coordena é direcionado para as competências colaborativas como o trabalho em equipe? Todos responderam afirmativamente. As respostas obtidas revelaram que as IES, no que se refere à eficácia do trabalho em grupo e aprendizagem com estudantes de outros cursos, procuram vencer os desafios, auxiliando no desenvolvimento de competências profissionais, os quais são essenciais para que possam aprender sobre o cuidado ao paciente. Na medida em que se altera a lógica tradicional da formação em saúde, insere-se o diálogo com as práticas docentes: os professores, com suas histórias de formação pautadas na especialização disciplinar, veem-se confrontados com seus desejos e possibilidades de aprenderem a ensinar de um modo mais participativo, interativo e criativo. Estas possibilidades podem ser ampliadas por meio do envolvimento dos docentes na construção de um PP inovador, tomando-os corresponsáveis pelos rumos e rotas da proposta de formação em saúde ${ }^{6}$.

No que diz respeito à integração ensino-serviço e ao trabalho em equipe desde os anos 1970, no Brasil são desenvolvidas propostas indutoras nesta direção. Em 2001, foram implementadas as Diretrizes Curriculares Nacionais dos Cursos de Graduação em Saúde (DCN), seguindo os princípios e diretrizes do SUS conforme a Lei 8.080/90. As DCNs representam um marco legal da articulação entre a saúde e educação e preconizam a formação para o trabalho em equipe na perspectiva da integralidade e da qualidade da comunicação entre a equipe e usuários/ famílias/comunidade ${ }^{7}$.

Com foco na aprendizagem compartilhada, as DCNs do curso de medicina publicadas em 2014, no Art. $7^{\circ} \S 3^{\circ}$, cita: "aprender interprofissionalmente, com base na reflexão sobre a própria prática e pela troca de saberes com profissionais da área da saúde e outras áreas do conhecimento, para a orientação da identificação e discussão dos problemas, estimulando o aprimoramento da colaboração e da qualidade da atenção à saúde". As diretrizes fornecem motivação para os educadores efetivarem a aprendizagem compartilhada, baseando-se em processos de comunicação interprofissional e 
iniciativas colaborativas centradas no paciente. Encorajam os cursos de medicina a refletir sobre o de seu conteúdo educacional, para que os egressos estejam aptos para atender às necessidades do sistema de saúde brasileiro?.

A perspectiva compreendida de educação interprofissional se dá "quando estudantes ou profissionais de dois ou mais cursos ou núcleos profissionais aprendem sobre os outros, com os outros e entre si”" e se aplica tanto para a graduação, das diferentes profissões na área da saúde, quanto para a educação permanente dos profissionais componentes de uma equipe de trabalho ${ }^{10,11}$.

Cabe ressaltar que as práticas colaborativas devem estreitar laços e diálogo entre os profissionais e, sobretudo, entre profissionais, usuários e população $0^{10}$. Esses movimentos de mudança referem-se à educação interprofissional em saúde (EIP) e a formação profissional inserida nas práticas de cuidado na Atenção Primária à Saúde (APS) apoiada na integração ensino-serviço, entendida como trabalho coletivo construído entre docentes, trabalhadores de saúde e estudantes, no intuito de assegurar maior resolutividade aos serviços prestados e qualidade à atenção à saúde ${ }^{12}$.

A EIP se compromete com o desenvolvimento de três competências - competências comuns a todas as profissões; competências específicas de cada área profissional e competências colaborativas, ou seja, o respeito às especificidades de cada profissão, o planejamento participativo, o exercício da tolerância e a negociação, num movimento de redes colaborativas. No Brasil, ainda são escassas as experiências sobre a EIP. Experiências de aprendizagem conjunta existem, mas não com o objetivo de desenvolvimento de competências para o interprofissionalismo. Atualmente, vivências e relatos de experiências de treinamento conjunto e aprendizagens compartilhadas, em políticas indutoras de mudanças na graduação, como o Pró-Saúde e o PET-Saúde, têm-se revelado como potenciais espaços de EIP $^{6}$.
$\mathrm{Na}$ sequência os pesquisados responderam à indagação: A IES capacita os docentes no aprofundamento da integração entre os diferentes cursos para acolher as demandas no sentido de melhorar a educação interprofissional na atenção da saúde do usuário? Nove coordenadores afirmam que sim (cinco de enfermagem e quatro de medicina) e dois coordenadores de medicina afirmaram que não. Nesta investigação, sobre a capacitação dos docentes para a integração interdisciplinar, fica uma lacuna a ser preenchida, visto que no questionamento anterior, sobre as competências colaborativas, houve unanimidade quanto às respostas - todas foram afirmativas. No entanto, existe na literatura relato que os princípios da educação interprofissional se aplicam tanto para a graduação das diferentes profissões de saúde, quanto para a educação permanente dos profissionais componentes de uma equipe de trabalho6. Como $18 \%$ das respostas indicou que não há capacitação para a integração curricular, percebe-se uma falha que deve ser sanada para que haja o comprometimento de uma formação para o interprofissionalismo, privilegiando o trabalho de equipe, a discussão de papéis profissionais, o compromisso na solução de problemas e a negociação na tomada de decisão.

A inclusão de metodologias ativas de ensinoaprendizagem tem se apresentado como uma escolha na probabilidade de se modificar a formação de profissionais na área da saúde, mas há fatores limitantes nesse procedimento. As Instituições de Ensino Superior que assumem o desafio de implantar metodologias inovadoras têm, a princípio, um desafio importante a vencer: a capacitação docente para as diversas funções demandadas pelo modelo. O docente necessita passar de transmissor de conhecimentos para mediador da aprendizagem dos discentes e esse é um processo complexo ${ }^{13}$.

A assistência baseada no modelo clássico traz barreiras ao trabalho em equipe, favorece a fragmentação da atenção, a produção de saúde centrada nos procedimentos e na doença, e não no 
usuário. Ainda, a concentração do poder de decisão na figura do médico coloca a atuação dos demais profissionais de forma periférica e com desigual valoração5. Arquitetar formas de trabalhar em equipe com orientação, que caminhe na direção da humanização, enseja, ainda, que o modelo de gestão seja repensado com a finalidade de aumentar a comunicação e o grau de integração entre os sujeitos, em que cada um exerça o seu papel valorizando seu saber e fazer e, ao mesmo tempo, se responsabilize pela direção da assistência oferecida. Desta forma, os profissionais podem se alinhar na direção da construção de um trabalho em equipe, pautado em relações de corresponsabilidade entre os diferentes profissionais envolvidos, na produção e promoção em saúde.

A questão seguinte respondida pelos coordenadores foi: A IES oferece alguma disciplina optativa, com docentes de diferentes cursos, favorecendo a articulação entre o ensino e a pesquisa com foco em atividades interprofissionais na atenção básica em saúde? Sete coordenadores, sendo cinco de enfermagem e dois de medicina, responderam que as IES oferecem disciplina optativa praticada por docentes de diferentes cursos, favorecendo a articulação entre o ensino e a pesquisa com foco em atividades interprofissionais, na atenção básica em saúde. Quatro coordenadores, destes dois de enfermagem e dois de medicina, afirmaram que as IES não oferecem a integração, por meio de disciplinas optativas.

Existe descompasso entre a formação dos profissionais de saúde e os princípios do SUS, que são focados na necessidade dos usuários, exigindo, assim, uma formação que valorize a integralidade, e não apenas focada na doença. Os futuros profissionais deverão trabalhar em equipe onde desempenharão funções distintas e, assim, durante a formação, devem ter o foco no usuário do sistema ${ }^{14}$.

A seguir foi feita a indagação relacionada à grade curricular: Os currículos dos cursos da área da saúde permitem uma formação para o trabalho em equipe e a integralidade no cuidado? Nas respostas dez coordenadores responderam sim e um coordenador de enfermagem respondeu não. A construção do currículo atualizado e adaptado à sociedade moderna permite às IES formarem profissionais mais preparados para organizar o cotidiano de trabalho, em diversas atuações na área da saúde.

A Lei de Diretrizes Curriculares Nacionais, aprovada em novembro de 2001, cujo texto enuncia os princípios e diretrizes do SUS, como elementos básicos na formação de um profissional integral, busca diminuir a lacuna existente entre a formação e a assistência individual. A reformulação das Diretrizes Curriculares para os cursos da área da saúde é datada de muito tempo, porém suscita uma discussão atual ${ }^{15}$. Estudos recentes, que mapearam a produção científica sobre Trabalho e Educação em Saúde no Brasil, apontaram que $71,2 \%$ das publicações referem-se à formação/capacitação dos profissionais de saúde. Essa extensa produção confirma a preocupação com a formação dos profissionais na área da saúde, um desafio imposto pelo trabalho em saúde na sociedade atual, ainda a ser suplantado ${ }^{17}$. Nos últimos anos, no Brasil, houve uma grande expansão do número de escolas e cursos na área da saúde, sobretudo, no setor privado, e, em consequência, observa-se o desencadeamento de reformas curriculares ${ }^{17}$. Entretanto, após mais de dez anos de existência da Lei de Diretrizes Curriculares Nacionais, a universidade brasileira, em seu regime hegemônico, submete os discentes a uma formação baseada em currículos fechados, menos interdisciplinares e especializados, pouco envolvidos com as políticas públicas de saúde, dificultando um eficiente trabalho em equipe ${ }^{18}$. Considerando tais pressupostos, falar da formação em saúde, como estratégia para a consolidação do SUS, implica refletir sobre as diretrizes curriculares como uma base conceitual, filosófica e metodológica, as quais direcionam uma nova proposta pedagógica, no processo de construção de um perfil profissiográfico. 
Estes devem ser dotados de competências e habilidades que sejam adequadas às referências nacionais e internacionais, para a formação de um profissional crítico-reflexivo, transformador da realidade social, agente de mudança e comprometido com a saúde da população.

Na sequência os coordenadores foram questionados sobre a participação da IES no Programa de Educação pelo Trabalho em Saúde (PET-Saúde): A IES participa do PET-Saúde promovendo o fortalecimento das ações de integração ensino-serviço-comunidade por meio de atividades que envolvam o ensino, a pesquisa e extensão universitária, e a participação social? Houve dez respostas afirmativas e apenas um coordenador de enfermagem afirmou que o Curso não participa do programa.

O Ministério da Saúde, em parceria com o Ministério da Educação, desenvolveu e implementou o Programa Nacional de Reorientação da Formação Profissional em Saúde (Pró-Saúde), com o compromisso de formar profissionais hábeis a atuar com qualidade e resolubilidade no SUS. No processo de avaliação do Pró-Saúde, foi observada a necessidade da inclusão do aluno no serviço de saúde, contribuindo com a efetivação da interação ensino-serviço. Assim, surge o PET-Saúde, criado por iniciativa dos Ministérios da Saúde e da Educação, a partir da Portaria Interministerial $\mathrm{n}$ ํ 1.802 . Todas essas iniciativas são exemplos de práticas bem-sucedidas destinadas a superar os desafios da educação de profissionais da área da saúde ${ }^{9}$.

Ao responder a pergunta: Na IES há atividade de Extensão que proporciona o trabalho em equipe e colaboração privilegiando a integração dos estudantes de enfermagem e medicina? Dez coordenadores afirmaram que há atividade de Extensão que proporciona a integração e um coordenador de enfermagem afirmou que a IES não oferece esta opção.

A Universidade Pública brasileira está construída sobre o trinômio ensino-pesquisa-extensão, cumprindo esta última um papel articulador entre o ensino e a pesquisa que viabiliza a relação transformadora entre Universidade e Sociedade. O processo educativo precisa de tempo para maturação, tempo necessário para dar sentido aos processos de aprendizagem. A construção do conhecimento está diretamente ligada entre $\mathrm{si}^{19}$.

Quando questionados: "Na IES há atividade de pesquisa que proporciona o trabalho em equipe e colaboração privilegiando a integração dos estudantes de enfermagem e medicina?" Nove coordenadores responderam de forma afirmativa, um afirmou que não e um não respondeu a questão.

A educação interprofissional estimula e fortalece para a colaboração e o trabalho em equipe, tornando o aluno um profissional habilitado para assistência de qualidade. Seu objetivo é garantir a formação de estudantes de graduação, na área da saúde, melhor preparados para a prática interprofissional. Os estudantes de graduação, nesta área, estão abertos para a aprendizagem compartilhada e o trabalho em equipe precisa ser norteado pelo investimento na criatividade, na busca de novos mecanismos, a fim de aprimorar a qualidade na produção de cuidado em saúde e da Formação Interprofissional ${ }^{20}$.

A atividade de pesquisa, na graduação, oportuniza, ao aluno, interagir com o objeto de pesquisa, ou seja, realizar atividades práticas que são pertinentes ao futuro profissional. O ensino complementa-se com os projetos de pesquisa, rompe as barreiras da sala de aula, problematiza a situação a ser estudada, sai do ambiente fechado da Universidade para a atuação realista presente, propicia que haja a troca de informações provenientes do ambiente primordial. Assim, o conteúdo passa a ser interprofissional necessitando de outros saberes para realizar o atendimento da demanda contribuindo integralmente para a prática interprofissional. Para que uma boa educação em saúde aconteça é necessário o contato com a realidade social e os problemas reais que os 
estudantes das áreas de saúde enfrentarão na sua rotina, após o término do curso.

A indagação sobre: "Em quais momentos, ou períodos, ocorrem atividades de integração entre os estudantes de enfermagem e medicina?" As respostas foram variadas. Seis coordenadores (três de enfermagem e três de medicina) responderam que as integrações se deram no início dos cursos, três no meio da graduação (dois de enfermagem e um de medicina), um no final da graduação (enfermagem) e um não respondeu (enfermagem).

A integração, como estratégia de aprendizagem interprofissional desenvolvida em universidades por meio de metodologias elaboradas e formalizadas, é possível em vários momentos na graduação. Independente do período, o processo ensinoaprendizagem poderá ser estabelecido a partir da integração entre o ensino e o serviço. Após iniciar a atividade curricular com embasamento teórico e, por meio da inserção dos discentes no serviço de saúde, pode-se induzir a novas formas de organização do trabalho em saúde, formando profissionais qualificados e com habilidades práticas para o atendimento às pessoas. Além disso, a relação interprofissional de troca de saberes entre discentes, docentes, profissionais do serviço e usuários pode contribuir para a formação de um novo perfil profissional, que atenda às necessidades vigentes de saúde de forma resolutiva, com profissionais realmente comprometidos em relação à qualidade nos serviços de saúde e que atenda às reais necessidades da população $0^{21}$.

A atividade interprofissional, por meio da atuação conjunta de profissionais de saúde, promove a prática de colaboração na prestação de serviços, com base na integralidade do sistema de saúde vigente, envolvendo pacientes e seus familiares, cuidadores e comunidades. Esta integração pode envolver trabalhos clínicos ou não clínicos, como a educação em saúde e as terapias de grupo, com ênfase na promoção em saúde em todos os níveis da rede de serviços. Embora fundamental, o trabalho interprofissional na área de saúde ainda é pouco explorado durante a graduação em cursos da saúde. Como recurso a essa importante prática, existem atividades de Extensão Universitária, que promovem a interação entre as mais variadas áreas de Saúde.

E, finalmente, com destaque na opinião dos participantes foi apresentada a pergunta: "De acordo com seu conhecimento e experiência profissional, qual momento seria propício para iniciar a integração entre os estudantes de enfermagem e medicina?". Oito participantes afirmaram que o momento mais adequado seria no início da graduação (cinco de enfermagem e três de medicina); um coordenador afirmou no meio (enfermagem); um respondeu que o período mais acertado seria no final da graduação (medicina), um não respondeu (enfermagem). A integração dos acadêmicos e docentes, dos diversos cursos de graduação da área da saúde, é dificultada pelo fato de os cursos possuírem níveis diferentes de inserção em atividades na atenção básica, bem como pela inexistência de disciplinas comuns para as graduações e pelo fato de os horários de aulas serem muito diversos, tornando difícil a realização de trabalhos interprofissionais ${ }^{22}$.

A criação de mais oportunidades de encontro entre os estudantes de graduação, das áreas envolvidas, possibilitaria uma vivência interprofissional entre eles, potencializando a integralidade como princípio da formação profissional.

Considerando as novas diretrizes curriculares do ensino médico e a relevância da prática na promoção de saúde e da atenção primária, especificamente o Programa Saúde da Família, um trabalho de pesquisa revelou uma experiência dos alunos do curso de medicina e enfermagem na integração entre ensino e serviço na Atenção Básica à Saúde. No artigo é descrito que a atuação conjunta dos estudantes de ambos os cursos, atuando com funções iguais na mesma atividade, reforçou a possibilidade e a importância do aprendizado. Na visão dos autores 
os olhares se somaram para atuar de acordo com os objetivos da Estratégia Saúde da Família para a promoção da saúde. Em todo o artigo não há descrição da escolha do período acadêmico, no entanto, observa-se que, por se tratar de atividade educativa integrada com a comunidade, os alunos estão iniciando as disciplinas de saúde coletiva ${ }^{23}$.

Os artigos utilizados neste trabalho, como referencial teórico no que tange à integração, mostram que na literatura, dentre os autores consultados bem como na pesquisa realizada no presente estudo, não existe um consenso de quando se deve iniciar a formação interprofissional em saúde, se bem que alguns autores sinalizaram que é melhor introduzir a integração durante o estágio ou na pós-graduação4. No entanto, há resultados encontrados em uma pesquisa que indicaram que os estudantes estão abertos à discussão e introdução à aprendizagem com integração, desde o início da graduação. As diferenças, competições de ego, as divergências, crenças e valores podem ser discutidos e minimizados ao longo do curso, propiciando a formação de profissionais habilidosos, interativos, competentes e preocupados com as necessidades do sistema de saúde e da qualidade do atendimento de seus pacientes.

\section{CONCLUSÕES}

O estudo realizado se propôs a identificar se ocorrem atividades, no processo de formação superior, que contemplam a integração entre os cursos de medicina e enfermagem com destaque no trabalho em equipe, centrado no paciente.

Identificou-se a existência de atividades integrativas em iniciativas curriculares e extracurriculares em todas as IES pesquisadas. Com exceção da oferta de disciplinas optativas, as respostas afirmativas das demais perguntas, com valores acima de $82 \%$, indicaram que existe alguma forma de integração entre os cursos pesquisados. De acordo com as DCNs dos cursos da saúde, as atividades colaborativas entre os futuros profissionais se fazem necessárias frente às demandas constantes exigidas nesta área. Acredita-se que a criação de mais oportunidades de encontro entre os estudantes de graduação, das áreas envolvidas, seja no ensino, na pesquisa ou na extensão, possibilitará uma vivência maior potencializando a integralidade como princípio da formação profissional.

Não houve um consenso entre os coordenadores quanto ao momento ideal para iniciar a integração entre os estudantes dos cursos pesquisados. Entretanto, a maioria dos pesquisados sinalizou o início da graduação como o melhor momento para articular as práticas pedagógicas que podem ser compartilhadas, entre os cursos pesquisados, proporcionando habilidades necessárias para um trabalho coletivo. Muitos desafios devem ser vencidos e novas estratégias podem ser traçadas, junto aos docentes e discentes, para estreitar o trabalho em equipe resultando em serviços de qualidade e, sobretudo, humanizado no atendimento à população.

\section{REFERÊNCIAS}

Peduzzi M, Norman IJ, Germani ACCG, Silva JAM, Souza GC. Educação interprofissional: formação de profissionais de saúde para o trabalho em equipe com foco nos usuários. Rev Esc Enferm. USP. 2013 ago; 47(4): 977-83.

2. Rodrigues LBB, Silva PCS, Peruhype RC, Palha PF, Popolin MP, Crispim JA, Pinto IC, Monroe AA, Arcencio RA. A atenção primária à saúde na coordenação das redes de atenção: uma revisão integrativa. Ciência e Saúde Colet. 2014 fev; 19(2): 343-52.

3. Reeves S. Porque precisamos da educação interprofissional para um cuidado efetivo e seguro. Interface - Comunicação, Saúde, Educação. 2016; 20(56):185-97.

4. Horsburgh M, Lamdin R, Williamson E. 'Multiprofessional learning: the attitudes of medical, nursing and pharmacy students to shared learning', Medical Education, Oxford. 2001; 35: 876-83.

5. Marin MJS, Lima EFG, Paviotti AB, Matsuyama DT, Silva LKD, Gonzalez C, Druzian S, Ilias M. Aspectos das fortalezas e fragilidades no uso das metodologias ativas de aprendizagem. Rev Bras Educ. Med. 2010 Jan/Mar; 34(1): 13-20

6. Batista NA. Educação Interprofissional em Saúde: Concepções e Práticas. Caderno FNEPAS. 2012; 2: 25-8.

7. Feuerwerker LCM, Capozzolo AA. Mudanças na formação 
dos profissionais de saúde: alguns referenciais de partida do eixo trabalho em saúde. In: Capozzolo AA, Casetto SJ, Hens AO. Organizadores. Clínica comum: itinerários de uma formação em saúde. São Paulo: Hucitec; 2013. p. 35-68.

8. Ministério da Educação (BR). Diretrizes Curriculares Nacionais do Curso de Medicina. Conselho Nacional de Educação. Câmara de Educação Superior. Resolução nº 3, de 20 de junho de 2014. Disponível em: http://www.fmb.unesp.br/ Home/Graduacao/resolucao-den-2014.pdf. Acesso em 07 de junho de 2018.

9. Freire Filho JR, Costa MV, Forster AC, Reeves S. New national curricula guidelines that support the use of interprofessional education in the Brazilian context: An analysis of key. J Interprof Care. 2017; 10(51): 1-8.

10 World Health Organization. Marco para ação em educação interprofissional e pratica colaborativa. Genebra: World Health Organization; 2010.

11. Baar H, Koppel I, Reeves S, Hammick M, Freeth D. Effective interprofessional education: arguments, assumption \& evidence. London: Blackwell, CAIPE, 2005. 180 p.

12. Silva JAM, Peduzzi M, Orchard C, Leonello VM. Educação interprofissional e prática colaborativa na Atenção Primária à Saúde. Rev Esc Enferm. USP; 2015; 49(Esp2): 16-24.

13. Ribeiro BB, Eckert JB, Figueiredo AC, Galhardi WMP, Campanaro CM. Enfermagem: Promovendo a Saúde da Criança. Rev Bras Educ Med. 2012; 36: 89-96.

14. González AD, Almeida MJ. Integralidade da saúde: norteando mudanças na graduação dos novos profissionais. Cienc Saúde Colet. 2010;15(3): 757-62.

15. Ministério da Educação (BR). Secretaria de Educação Superior. Diretrizes Curriculares para os Cursos de Graduação. Resolução CNE/ CES № 3, de 7 de novembro de 2001.Disponível em: http://www.mec.gov.br/sesu/diretriz.htm [Acesso em 24 abril 2017].

16. Pinto ICM, Esperidião MA, Silva VI, Soares CM, Santos L, Fagundes TLQ. Trabalho e educação em saúde no Brasil: tendências da produção científica entre 1990-2010. Cienc Saúde Colet. 2013; 18(6):1525-34.

17. Teixeira CF, Coelho MTAD, Rocha MND. Bacharelado interdisciplinar: uma proposta inovadora na educação superior em saúde no Brasil. Cienc Saúde Colet. 2013; 18(6):1635-46.

18. Almeida Filho NM. Contextos, impasses e desafios na formação de trabalhadores em Saúde Coletiva no Brasil. Cienc Saúde Colet. 2013; 18(6): 1677-82
19. Toassi RFC, Lewgoy AMB. Práticas integradas em Saúde I: Uma experiència inovadora de integração intercurricular e interdisciplinar. Interface: Communication, Health, Education, 2016.

20. Aguilar-Da-Silva RH, Scapin LT, Batista N. A. Avaliação da formação interprofissional no ensino superior em saúde: aspectos da colaboração e do trabalho em equipe. Avaliação: Revista da Avaliação da Educação Superior (Campinas). 2011 mar; 16(1): 165-84.

21. Albuquerque VS, Gomes AP, Rezende CHA, Sampaio MX, Dias OV, Lugarinho RM. A integração ensino-serviço no contexto dos processos de mudança na formação superior dos profissionais da saúde. Rev Bras Educ Med. 2008; 32(3): 356-62.

22. Pizzinato A, Gustavo AS, Santos BRL, Ojeda BS, Ferreira E, Thiesen FV, Creutzberg M, Altamirano M, Paniz O, Corbellini VL A. integração ensino-serviço como estratégia na formação profissional para o SUS. Rev. bras. educ. med. 2012 Jan./Mar ; 36(1): 170-77.

23. Ribeiro BB, Eckert JB, Figueiredo ACM, Galhardi WMP, Campanaro CM. Experiência de ensino em medicina e enfermagem: promovendo a saúde da criança. Rev Bras Educ Med. 2012 Mar; 36(1): 89-96. 